\title{
Moderate inundation stimulates plant community assembly in the drawdown zone of China's Three Gorges Reservoir
}

Zhongli Chen ${ }^{1,2^{*}} \mathbb{D}$, Xingzhong Yuan ${ }^{3}$, Martina Roß-Nickoll ${ }^{1,2}$, Henner Hollert ${ }^{1,2,4,5,6}$ and Andreas Schäffer ${ }^{1,2,5}$

\begin{abstract}
Background: While a dam is constructed to adjust and store water resources, it has negative impacts on biodiversity of the corresponding ecosystems. In particular, the dam regulation induces water-level fluctuations (WLFs), resulting in remarkable effects on the riparian vegetation succession of the drawdown zone ecosystem. These riparian plant responses play important roles in the biodiversity conservation. However, in-depth investigative adequate studies are still lacking. The objective of this study was to assess the community assembly under the anti-seasonal WLFs of China's Three Gorges Reservoir (TGR). To analyze the WLFs' impacts on plant community, the drawdown zone of the TGR was divided into four sub-zones (zone I, II, III, and IV) according to the inundation periods. The community biomass, height, total coverage, and species diversity in each sub-zone were surveyed. To detect the response of individual plant to the WLFs, dominant plants of Echinochloa crusgalli, Setaria viridis, Bidens pilosa, and Xanthium sibiricum were selected as targeted species to compare the plant's morphological and physiological traits between non-flooded area and the moderately inundated area.
\end{abstract}

Results: The peaks of community biomass (1859.62 $\pm 663.77 \mathrm{~g})$, total coverage $(103.93 \pm 11.81 \%)$, and diversity indexes were found in zone II that experienced 90 days of inundation. Community height and total coverage were both significantly negatively correlated to the inundated gradients. Generalized linear models and quadratic regression analyses revealed that community biomass, height, and total coverage were strongly related to the inundated gradients, implying that the inundation is the major factor contributing to the variation of the riparian vegetation patterns. The values of morphological traits (plant height and biomass) in the zone II were higher than those in the non-flooded zone, and were significantly positively correlated with physiological traits.

Conclusions: Community structure, diversity, and functional traits analysis indicated that the drawdown zone referencing to the 90-day inundation was suitable for the plant community establishment. Results on plant functional traits suggest the adaption of riparian plants to the TGR hydrological regime. However, further investigative studies with more plant species are necessary to elucidate their adaptation mechanisms.

Keywords: Water-level-fluctuating zone, Anti-seasonal inundation, Community assembly, Plant functional traits, The Three Gorges Reservoir (TGR)

*Correspondence: zhongli.chen@cqu.edu.cn

1 Key Laboratory of the Three Gorges Reservoir Region's Eco-Environment, Ministry of Education, Chongqing University, 400045 Chongqing, People's Republic of China

Full list of author information is available at the end of the article

\section{Background}

Riparian plants growing at the drawdown zone of rivers, lakes, and reservoirs, are the primary indicator of the riparian habitat [1]. They provide a corridor for biota, their above-ground biomass modifies flow and thus controls sediments and nutrients transport [2]. In addition, they moderate water temperature, stabilize 
riverbanks, and provide food for humans [3]. Vegetation is a critical portion of the riparian ecosystems, of which the succession is involved in the riverine evolution process [4]. The riparian plant community assembly is strongly influenced by the water-level fluctuations (WLFs) induced by natural and/or artificial flooding events. The WLFs with their extent, flow, duration of submergence and frequency, etc., usually form a unique pattern in lakes and rivers that affect riparian plant in a large scales including morphological changes, physiological variations as well as shifts in growth rate and/or growth form [5]. The inundation of the WLFs not only alters the soil physical-chemical characteristics and patterns of soil microorganism, but also the changes of plant uptake and accumulation of water and substrates as well as the light availability and temperature which are important factors for plant photosynthesis. Therefore, an understanding of plant community assembly in relation to the inundation changes is of great importance. Studies have reported the changes of diversity, patterns of plant community, soil seedbank and plant individual properties such as growth form and reproduction in response to natural flooding [5-9]. Although the knowledge governing the plant community assembly under disturbance is growing, gaps still exist on plant's adaption to the anti-seasonal WLFs, in particular with those infrastructural developments such as dam construction with inundation period ranging from weeks to months [10].

The Three Gorges Dam on the upper reaches of the Yangtze River, which is the dam (2309 $\mathrm{m}$ in length and $185 \mathrm{~m}$ in height) with the largest installed capacity of hydropower in the world, started to function in 2010. As a result, the capacities of flooding control, navigation as well as hydropower generation have remarkably increased. Simultaneously, the corresponding reservoirthe Three Gorges Reservoir (TGR) has been created with an area of $58,000 \mathrm{~km}^{2}$ in total. The new hydrological regime of the TGR is seasonal reverse, with the water level fluctuating from $145 \mathrm{~m}$ above sea level during summer and up to $175 \mathrm{~m}$ during winter [11]. Field surveys have recently reported a decline of plant diversity and vegetation dominated by herbaceous in the drawdown zone of the TGR in contrast to its pre-dam patterns [12-15], which differ from the other vegetation patterns induced by dam regulation [16-20]. Understanding the newly created ecosystem process of the TGR is an urgent and crucial issue for environmental conservation and ecosystem sustainable management in the reservoir region. The regulation of TGR thereby provides us an opportunity to explore the mysterious realms regarding the effects of anti-seasonal hydrology on riparian vegetation.
Community assembly is mainly governed by abiotic gradients, propagule pressure, and species interactions [21]. The abiotic gradients, such as anti-seasonal WLFs, are considered as a disturbance to riparian plants, which vary in inundation frequency, period, and depth. The highest diversity and productivity are usually found in the intermediate disturbance zones with respect to time and/or space, following the intermediated disturbance hypothesis (IDH) $[22,23]$. During plant growth, the complete life history is important than that of propagule pressure. Species interactions are the results of fitness during plant life history under anti-seasonal fluctuation, which are driven by water fluctuation disturbance, resources use efficiency, and inter- and intra-species competition. The individual properties during plant growth therefore could be assessed from the variations of plant functional traits $[24,25]$. Plant changes, for instance shifts of growth rate and/or growth form, are often the results of changing physiological processes and are adaptive responses in basic phenomena such as photosynthesis, water and nutrient transport [5]. The contribution of factors for community assembly differs between each other, as well as their corresponding integrated effects. Identification of the main effect on community assembly may help to predict the community succession along with the TGR hydrological regime.

The aims of the current study are to demonstrate the response of riparian vegetation to the anti-seasonal fluctuation resulting from regulation of the TGR. We investigated community structure including biomass, height and total coverage, and diversity along inundation gradients (IGs). In addition, we tested the variations of plant functional traits of dominant plants between upland zone (UZ) that are non-inundated and zone II with submerged period corresponding to intermediate IG. To achieve this goal, we hypothesized that (1) the patterns of riparian plant community structure (biomass, height, and total coverage) and diversity of the TGR follow the IDH; (2) the community assembly is mainly driven by WLFs and (3) plant changes could be linked with functional traits. To our knowledge, this study is the first one linking plant community assembly and plant functional traits to antiseasonal WLFs, which promotes understanding the vegetation succession on the drawdown zone ecosystem process.

\section{Methods}

\section{Study area and the TGR inundation conditions}

The TGR area is characterized by a subtropical monsoon climate with average annual temperature of $15{ }^{\circ} \mathrm{C}-18{ }^{\circ} \mathrm{C}$ and mean annual precipitation of $1000-1300 \mathrm{~mm}$. The highest temperature in summer is up to $35{ }^{\circ} \mathrm{C}$ or even higher for several weeks, thereby vegetation in 
the drawdown zone of the TGR must endure summer drought and winter flooding. The soil types are red soil, purplish soil, yellow soil and paddy soil [26].

The dam construction was started in 1994 and the water level was raised to $139 \mathrm{~m}$ since 2003 , which is $60 \mathrm{~m}$ higher than that of the natural water level of the Yangtze River. Experimental submergence of water up to $156 \mathrm{~m}$ in winters of 2006 and 2007 and $173 \mathrm{~m}$ in winters of 2008 and 2009 was implemented with the water level declining to $145 \mathrm{~m}$ in summers. Since 2010, the dam started full function with $30 \mathrm{~m}$ fluctuation ranging from $145 \mathrm{~m}$ to $175 \mathrm{~m}$ [26]. The annual anthropogenic water-level inundation lasts more than 8 months, the rise and fall of the water level cost time so the duration of winter submergence declines with elevation, i.e., the drawdown zone of lower elevations is inundated for a longer time. Under such inundation condition, plants at the drawdown zone of the TGR are highly affected, but could still germinate and grow when the inundation recedes (summer). Until the summer of 2012, the drawdown area below $156 \mathrm{~m}$ elevation has been inundated 7 times while that between 156 and $175 \mathrm{~m}$ is 4 times. In addition, during summer season, the drawdown area from $145 \mathrm{~m}$ to approximately
$160 \mathrm{~m}$ is usually afflicted by natural floods from days to approximately 2 weeks.

\section{Community properties survey}

Field survey was conducted in the TGR region in August 2012. We selected sampling sites in the whole reservoir area distributing from the Xiangxi River estuary (Hubei province) to the city of Chongqing (Fig. 1), where most sites were correlated to our previous study [13]. By analyzing the inundation record from 2008 to 2011 (http:// www.ctg.com.cn/inc/sqsk.php), we categorized the drawdown area into four sub-zones reflecting different immersion periods (zone I: $170-175 \mathrm{~m}$ of elevation, zone II: $165-170 \mathrm{~m}$, zone III: $160-165 \mathrm{~m}$, and zone IV: $145-160 \mathrm{~m})$. Zone I, II and III are submerged during winter season, besides, zone III is inundated during in case of severe natural flooding in summer. Zone IV is affected by both winter submergence and summer natural flooding. Meanwhile, the upland zone (UZ) between $175 \mathrm{~m}$ and $180 \mathrm{~m}$ was included for comparison. In each site, sets of corresponding transects that are parallel to the water level with $50 \mathrm{~m}$ in length were defined in each subzone and the corresponding uplands. The representative

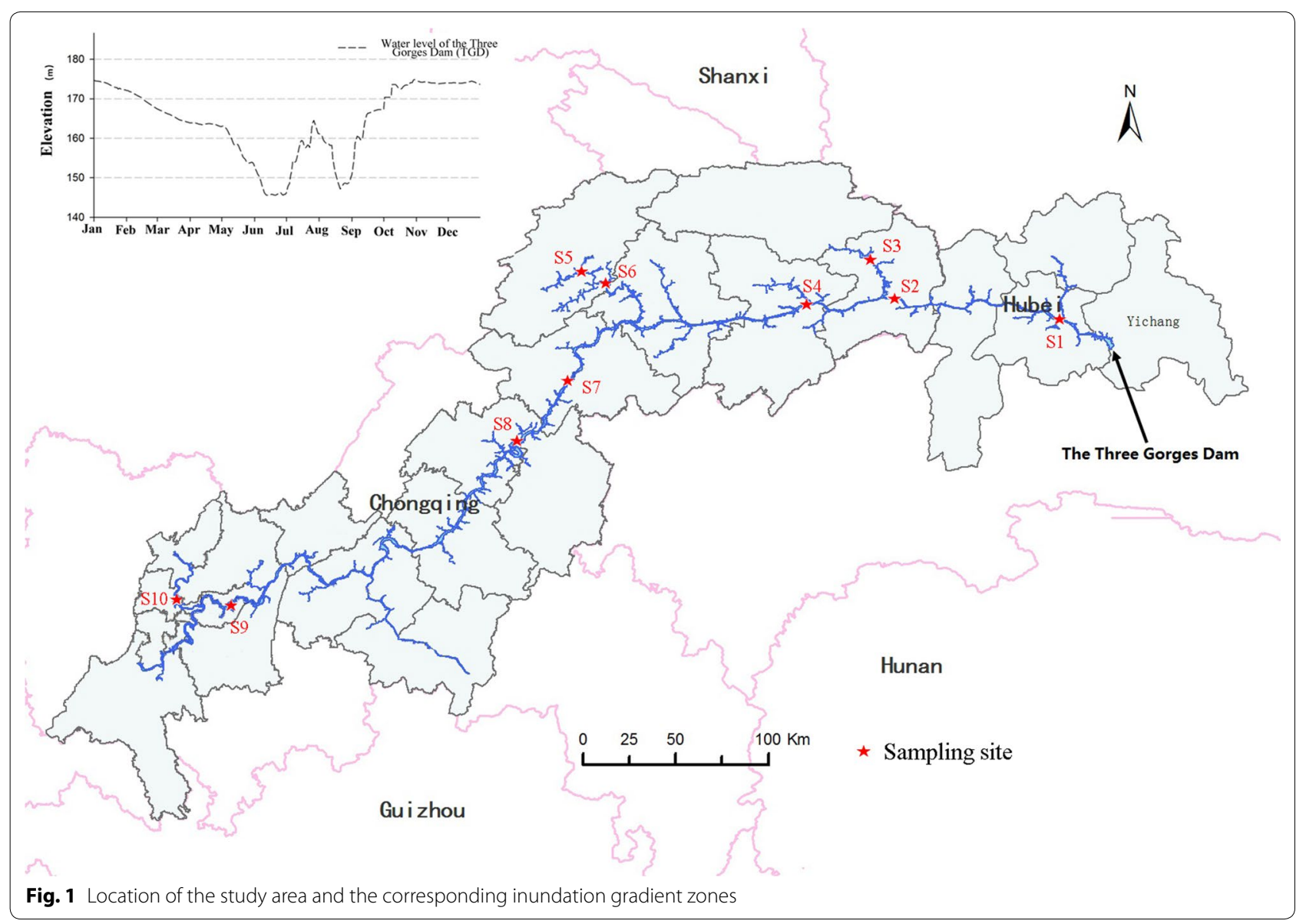


vegetation in each transect was selected and six $1 \times 1 \mathrm{~m}$ quadrats were randomly chosen for investigating plant species, abundance, species average height, coverage (visually estimated), and plant aboveground biomass (obtained by harvesting). Plant species within the $50-\mathrm{m}$ transects were recorded and the relative frequency of each species was calculated in order to select the species for further study. The slope gradients (SGs) of each quadrats were also recorded according to the technical regulations for land use status survey (1984) (five gradients: $\leq 2^{\circ}, 2-6^{\circ}, 6-15^{\circ}, 15-25^{\circ}$ and $>25^{\circ}$ ) [27]. Due to the fact that the height of the drawdown zone is less than $30 \mathrm{~m}$ in the tail area of the reservoir, a total of $10 \mathrm{sam}$ pling sites and 196 quadrats were finally established in the current study.

In order to examine the effect of IGs on riparian vegetation, we employed the indicators with community structure (biomass, height and total coverage) and diversity (species Richness, Shannon-Wiener index, Simpson index and Pielou index) in quadrats. For each indicator, data from the six quadrats in the same elevation zone of each sampling site were averaged. Generalized linear models (GLMs) were performed to analyze the abiotic effects on the riparian vegetation community properties, in which community biomass, total coverage, height and community diversity were used as dependent variations; simultaneously, the IGs, SGs and the sampling sites along the reservoir longitudinal gradients (LGs) were selected as fixed factors. Since we made an a priori assumption that community structure and diversity would follow the IDH; hence, quadratic regression analyses were used to determine if disturbance of IGs were significantly and unimodally related to community properties described above.

\section{Plant functional traits investigation}

After the vegetation survey described above, plants dominantly distributed both at the zone II where they were submerged for 90 days per year and the surrounding UZ $(175-180 \mathrm{~m})$ were chosen as the specimens for which the individual aboveground biomass and plant height (maximum height) were recorded. For each species, 10 healthy plants with fully extended leaves were selected randomly from the drawdown area and measured for photosynthetic characteristics with three replicates. Gasexchange measurements of the net photosynthetic rate $\left(P_{n}\right)$ were made from different healthy leaf tissues from 9:00 to 12:00 a.m. using a portable photosynthesis system (Yaxin-1102, Beijing Yaxinliyi Science and Technology, Beijing, China) under natural solar irradiance of 1500 $1800 \mu \mathrm{mol}\left(\mathrm{m}^{2} \mathrm{~s}\right)^{-1}$. The changes in the transpiration rate $\left(T_{r}\right)$, stomatal conductance $\left(C_{\text {leaf }}\right)$ and intercellular $\mathrm{CO}_{2}$ concentration $\left(\mathrm{CO}_{2 \text { int }}\right)$ were recorded simultaneously.
Each selected leaf was examined for $15 \mathrm{~s}$, followed by an interval of $25 \mathrm{~s}$, and the cycle was repeated twice. Measurements in the surrounding upland area were conducted in parallel.

\section{Data analysis}

With significant difference test, in case of the assumption of homogeneity of variance was met, the differences of the community properties along the IGs were tested by one-way ANOVA, in other case, the Kruskal-Wallis $H$ test was employed. The correlations among plant matrix and environmental variables were analyzed using Pearson correlation analysis at the $95 \%$ confidence level. The significant differences in the plant functional traits between zone II and the UZ were analyzed and the correlations within trait-parameter were performed with the same protocol as above. The GLMs, quadratic regression analyses and the other statistical analyses were performed using IBM SPSS 20.0 [28].

\section{Results}

\section{Distribution patterns of community structure and a-diversity}

We found that annual and perennial herbaceous plants were dominant species of the drawdown area. 190 plant species in 144 genera and 53 families were identified, among which Gramineae (15.26\% of 190 species), Asteraceae (12.63\%), Cyperaceae (6.32\%) and Leguminosae (5.26\%) were the most quantitatively abundant families, which is comparable to our previous study [13]. Four species, Echinochloa crusgalli, Setaria viridis, Bidens pilosa and Xanthium sibiricum with relative frequencies up to $27.55 \%, 29.1 \%, 27.55 \%$ and $20.1 \%$, respectively, were selected for further study on functional traits. The $\alpha$-diversity and community structure (biomass and total coverage) peaked at zone II, with the community height as an exception (Fig. 2). Regarding the diversity matrix (Fig. 2a), Shannon index fluctuated from $0.59 \pm 0.40$ (zone IV) to $0.88 \pm 0.47$ (zone II), Simpson index ranged from $0.35 \pm 0.23$ (zone IV) to $0.45 \pm 0.24$ (zone II), Pielou index amounted from $0.42 \pm 0.27$ (zone IV) to $0.51 \pm 0.23$ (zone II) and Richness index fluctuated from $2.83 \pm 1.76$ (zone IV) to $4.43 \pm 2.48$ (zone II). However, the differences did not vary significantly along IGs, which are different from a previous study [26]. With community structure, the variations along the IGs were very significant (biomass, $P<0.001$; height and total coverage, $P<0.001$ and $P<0.001$, respectively), the average total coverage were between $103.93 \pm 11.81 \%$ (zone II) and $44.39 \pm 35.46 \%$ (zone IV) (Fig. 2b), the averaged biomass ranged from $674.18 \pm 846.94 \mathrm{~g}$ in zone IV to $1859.62 \pm 663.77 \mathrm{~g}$ in zone II (Fig. 2c) and the average 

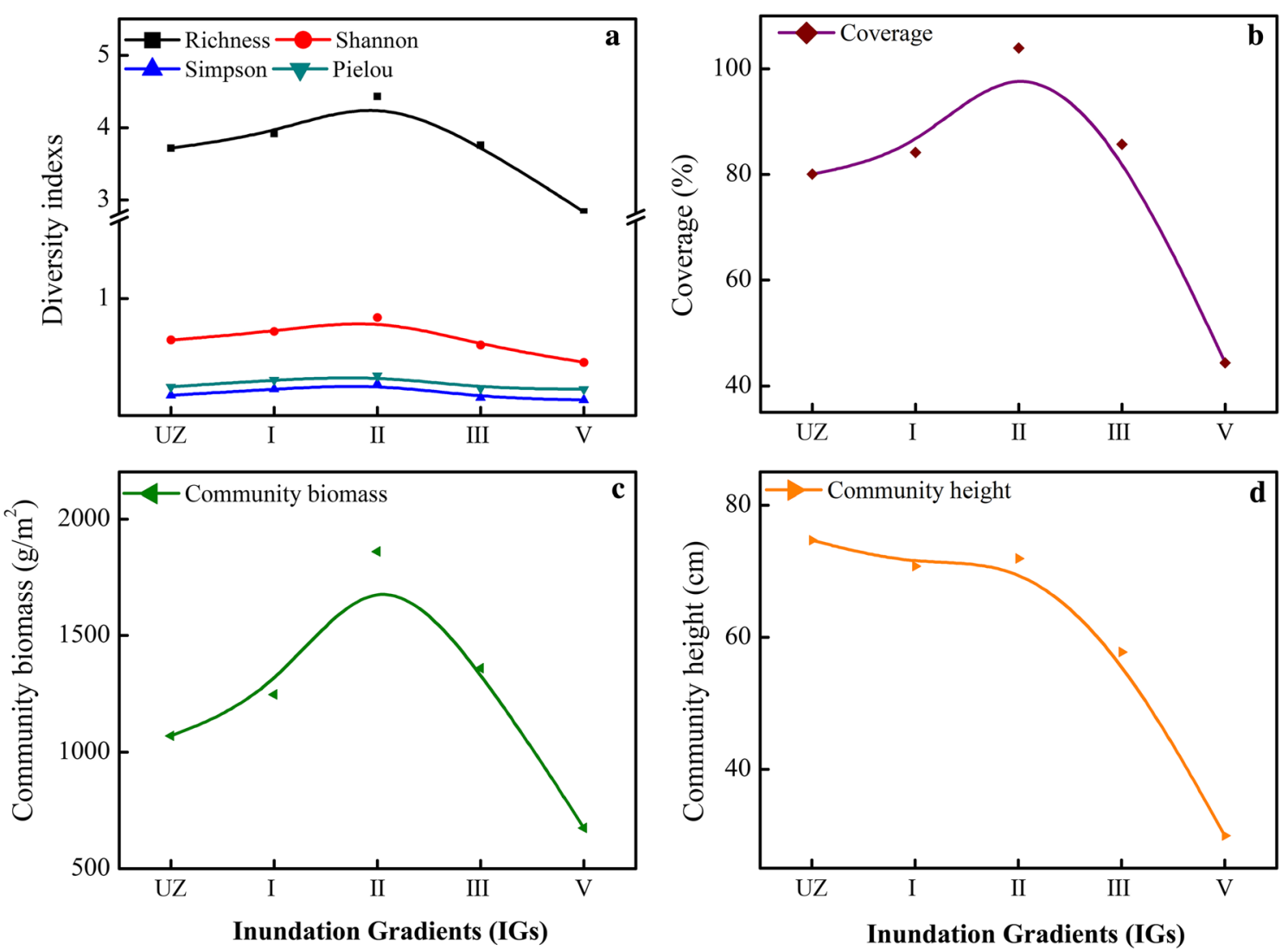

Fig. 2 Community structure and diversity along the inundation gradients (IGs) of the TGR area

Table 1 Correlations of plant community structure, a-diversity along with inundation gradients

\begin{tabular}{|c|c|c|c|c|c|c|c|c|}
\hline & IGs & Biomass & Height & Coverage & Shannon & Simpson & Pielou & Richness \\
\hline IGs & 1 & - & - & - & - & - & - & - \\
\hline Biomass & 0.002 & 1 & - & - & - & - & - & - \\
\hline Height & $-0.251^{* *}$ & $0.409^{* *}$ & 1 & - & - & - & - & - \\
\hline Coverage & $-0.150^{*}$ & $0.428 * *$ & $0.191 * *$ & 1 & - & - & - & - \\
\hline Shannon & -0.070 & $-0.226^{*}$ & -0.120 & -0.048 & 1 & - & - & - \\
\hline Simpson & -0.045 & $-0.252^{*}$ & $-0.147^{*}$ & -0.090 & $0.977^{* *}$ & 1 & - & - \\
\hline Pielou & -0.035 & $-0.279^{*}$ & -0.149 & -0.130 & $0.945 * *$ & $0.984^{* *}$ & 1 & - \\
\hline Richness & -0.073 & $-0.176^{*}$ & -0.042 & 0.106 & $0.804^{* *}$ & $0.691^{* *}$ & $0.613^{* *}$ & 1 \\
\hline
\end{tabular}

$\mathrm{IGs}$, inundation gradients

${ }^{*} P<0.05$, ${ }^{*} P<0.01$

community height amounted from $74.66 \pm 58.05 \mathrm{~cm}$ in UZ to $29.90 \pm 7.98 \mathrm{~cm}$ in zone IV (Fig. 2d).

\section{Relationships among community properties}

The correlations of community properties along the IGs varied significantly (Table 1). Community height and total coverage were both significantly negatively correlated to the IGs $(r=-0.254, P<0.001$ and $r=-0.145$,
$P<0.05$, respectively). Community biomass was significantly positively correlated to the height and total coverage, while the negative correlations were found with diversities (Shannon, Simpson, Pielou and Richness indexes: $r=-0.226, P<0.01 ; r=-0.252, P<0.001$; $r=-0.279, P<0.001$ and $r=-0.176, P<0.05$, respectively). The results of GLMs (Table 2) revealed a highly significant effect of IGs on community biomass, height 
Table 2 GLMs on the effects of environmental variables on riparian vegetation of the TGR

\begin{tabular}{|c|c|c|c|c|c|c|c|}
\hline \multirow[t]{2}{*}{ Source } & \multicolumn{2}{|l|}{ IGs } & \multicolumn{2}{|l|}{ LGs } & \multicolumn{2}{|l|}{ SGs } & \multirow{2}{*}{$\begin{array}{l}\text { IEs } \\
P\end{array}$} \\
\hline & $F$ & $P$ & $F$ & $P$ & $F$ & $P$ & \\
\hline Biomass & 7.744 & $<0.0001$ & 1.730 & 0.088 & 0.922 & 0.453 & $>0.05$ \\
\hline Height & 10.026 & $<0.0001$ & 10.667 & $<0.0001$ & 0.519 & 0.722 & $\mathrm{HGs}+\mathrm{LGs}<0.0001$ \\
\hline Coverage & 13.303 & $<0.0001$ & 1.721 & 0.090 & 0.590 & 0.670 & $>0.05$ \\
\hline Richness & 3.169 & 0.016 & 2.667 & 0.007 & 1.017 & 0.401 & $>0.05$ \\
\hline Shannon & 1.641 & 0.168 & 4.906 & $<0.0001$ & 0.976 & 0.423 & $>0.05$ \\
\hline Simpson & 0.838 & 0.504 & 5.816 & $<0.0001$ & 0.903 & 0.464 & $>0.05$ \\
\hline Pielou & 0.658 & 0.622 & 6.299 & $<0.0001$ & 0.495 & 0.740 & $>0.05$ \\
\hline
\end{tabular}

IGs, inundation gradients; LGs, longitudinal gradients; SGs, slope gradients; IEs, interaction effects

Table 3 Quadratic analyses for community parameters regressed with the inundation gradients of the TGR

\begin{tabular}{|c|c|c|c|c|c|c|c|c|c|}
\hline \multirow[t]{2}{*}{ Dependent variables } & \multirow[t]{2}{*}{ Equation } & \multicolumn{5}{|c|}{ Model summary } & \multicolumn{3}{|c|}{ Parameter estimates } \\
\hline & & $R$ square & $F$ & $\mathrm{df1}$ & $\mathrm{df2}$ & $P$ & Constant & $b 1$ & $b 2$ \\
\hline $\log _{10}$ (biomass) & Quadratic & 0.224 & 27.881 & 2 & 193 & $<0.0001^{* *}$ & 2.783 & 0.459 & -0.135 \\
\hline Height & Quadratic & 0.083 & 8.716 & 2 & 193 & $<0.0001^{* *}$ & 72.277 & 6.236 & -3.965 \\
\hline Coverage & Quadratic & 0.177 & 20.727 & 2 & 193 & $<0.0001 * *$ & 74.708 & 26.185 & -7.965 \\
\hline Richness & Quadratic & 0.033 & 3.285 & 2 & 193 & $0.040^{*}$ & 3.613 & 0.713 & -0.222 \\
\hline Shannon & Quadratic & 0.021 & 2.034 & 2 & 193 & 0.134 & 0.725 & 0.124 & -0.041 \\
\hline Simpson & Quadratic & 0.013 & 1.261 & 2 & 193 & 0.286 & 0.382 & 0.055 & -0.017 \\
\hline Pielou & Quadratic & 0.010 & 0.970 & 2 & 193 & 0.381 & 0.440 & 0.052 & -0.016 \\
\hline
\end{tabular}

* indicates quadratic regressions that were significant at $P<0.05$; ${ }^{* *}$ indicate quadratic regressions that were significant at $P<0.01$

and total coverage, whereas spatial heterogeneity of large scale (LGs in the current study) strongly affected the community diversity. The effects of SGs on community properties were not significant. Additionally, we only found a significant interaction effect between IG and LG on community height. While quadratic regression analyses (Table 3) showed that the community biomass, height and total coverage were strongly related to the IGs, the richness was significantly correlated with the community diversity. Overall, the IG was the major factor that led to the variation of the riparian vegetation patterns in the drawdown area of the TGR.

\section{Plant morphological and physiological functional traits}

The height and biomass of individual dominant plants in the zone II of the drawdown area were both higher than those in the UZs (Fig. 3). The differences in plant height were highly significant for $X$. sibiricum and B. pilosa $(P<0.001)$ and that for $S$. viridis was significant $(P<0.05)$. However, no significant differences were found for biomass $(P>0.05)$, except that of B. pilosa. Regarding the photosynthetic capacity of $P n, T_{r}, C_{\text {leaf }}$, and $\mathrm{CO}_{2 \text { int }}$ (Fig. 4), $P_{n}$ of E. crusgalli was $17.0 \pm 31.8 \mu \mathrm{mol} / \mathrm{m}^{2} \mathrm{~s}$ in the $\mathrm{FZ}$, which was significantly higher than that in the UZ $(4.7 \pm 7.7 \mu \mathrm{mol} /$ $\left.\mathrm{m}^{2} \mathrm{~s}, P=0.029\right) . P_{n}$ of $X$. sibiricum in the zone II was $13.7 \pm 10.2 \mu \mathrm{mol} / \mathrm{m}^{2} \mathrm{~s}$ and slightly higher than that in the UZ $\left(13.6 \pm 9.3 \mu \mathrm{mol} / \mathrm{m}^{2} \mathrm{~s}, P=0.975\right)$. In contrast, results found in $S$. viridis and $B$. pilosa, ranged from $4.0 \pm 4.9 \mu \mathrm{mol} / \mathrm{m}^{2} \mathrm{~s}$ to $10.6 \pm 16.3 \mu \mathrm{mol} / \mathrm{m}^{2} \mathrm{~s}$ for S. viridis $(P=0.028)$ and from $3.4 \pm 2.6 \mu \mathrm{mol} / \mathrm{m}^{2} \mathrm{~s}$ to $6.1 \pm 10.9 \mu \mathrm{mol} / \mathrm{m}^{2} \mathrm{~s}$ for $B$. pilosa $(P=0.365)$ in the zone II and UZ, respectively (Fig. 4a). Regarding $T_{r}$ (Fig. 4b), higher $T_{r}$ in the zone II were found with $E$. crusgalli $\left(2.75 \pm 0.81 \mathrm{mmol} / \mathrm{m}^{2} \mathrm{~s}, P=0.685\right)$ and $S$. viridis $\left(2.72 \pm 0.77 \mathrm{mmol} / \mathrm{m}^{2} \mathrm{~s}, P=0.153\right)$ than that in the UZ. The $T_{r}$ for $B$. pilosa in the UZ was found to be $3.01 \pm 2.0 \mathrm{mmol} / \mathrm{m}^{2} \mathrm{~s}$, which is significantly higher than that in the zone II $\left(1.4 \pm 0.9 \mathrm{mmol} / \mathrm{m}^{2} \mathrm{~s}, P=0.0001\right)$. The $T_{r}$ for $X$. sibiricum in the UZ was determined as $6.2 \pm 6.3 \mathrm{mmol} / \mathrm{m}^{2} \mathrm{~s}$ which is higher than that in the zone II $\left(4.3 \pm 4.4 \mathrm{mmol} / \mathrm{m}^{2} \mathrm{~s}, P=0.153\right)$. With respect to E. crusgalli and $S$. virids in the zone II, the $C_{\text {leaf }}$ (Fig. 4c) were significantly higher than those in the UZ, that is $90.5 \pm 32.0 \mathrm{mmol} / \mathrm{m}^{2} \mathrm{~s}$ and $67.3 \pm 26.5 \mathrm{mmol} / \mathrm{m}^{2} \mathrm{~s}$ for E. crusgalli $(P=0.002)$ and $84.6 \pm 34.8 \mathrm{mmol} / \mathrm{m}^{2} \mathrm{~s}$ and $64.7 \pm 53.3 \mathrm{mmol} / \mathrm{m}^{2} \mathrm{~s}$ for $S$. virids $(P=0.037)$, respectively. Contrary results were obtained from $B$. pilosa 

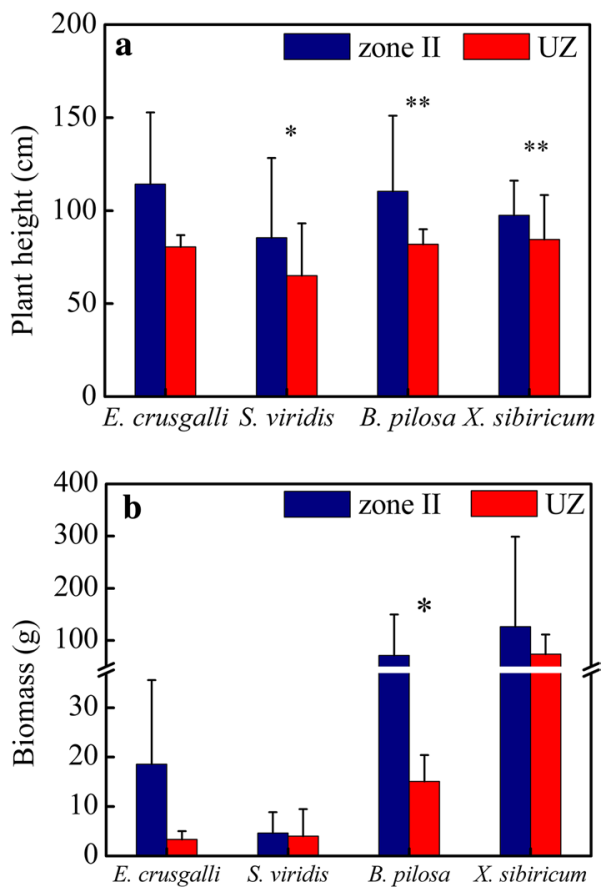

Fig. 3 Morphological traits of plant height (a) and plant biomass (b) of the selected dominant plants between zone II and the corresponding upland zone (UZ) of the TGR. * indicates difference of plant trait between zone II and UZ was significant at $P<0.05$; ** indicates difference of plant trait between zone II and UZ was very significant at $P<0.01$

and $X$. sibiricum, amounting to $55.4 \pm 32.4 \mathrm{mmol} / \mathrm{m}^{2} \mathrm{~s}$ and $77.2 \pm 39.5 \mathrm{mmol} / \mathrm{m}^{2} \mathrm{~s}$ for $B$. pilosa $(P=0.014)$ and $193.7 \pm 64.6 \mathrm{mmol} / \mathrm{m}^{2} \mathrm{~s}$ and $211.1 \pm 72.7 \mathrm{mmol} /$ $\mathrm{m}^{2} \mathrm{~s}$ for $X$. sibiricum $(P=0.293)$ in the zone II and UZ, respectively. Figure $4 \mathrm{~d}$ shows higher concentrations of $\mathrm{CO}_{2 \text { int }}$ in E. crusgalli (239.5 \pm 157.7 ppm, $\left.P=0.169\right), B$. pilosa $(256.3 \pm 125.1 \mathrm{ppm}, P=0.790)$ and $X$. sibiricum (256.6 $\pm 65.2 \mathrm{ppm}, P=0.789)$ in the UZ compared to those in the zone II, amounting to $177.7 \pm 210.2 \mathrm{ppm}$, $248.7 \pm 112.3 \mathrm{ppm}, 252.3 \pm 66.4 \mathrm{ppm}$ for E. crusgalli, B. pilosa, X. sibiricum, respectively. $\mathrm{CO}_{2 \text { int }}$ of $S$. viridis was $204.1 \pm 122.3 \mathrm{ppm}$ in the zone II, which is significantly higher than that in the UZ $(32.6 \pm 48.2 \mathrm{ppm}$, $P=0.0001)$.

Plant biomass was positively correlated with $T_{r}$ $(r=0.544, P=0.001), \quad C_{\text {leaf }}(r=0.784, P=0.0001)$ and height $(r=0.619, P=0.0001$ ) (Table 4$)$. Significant correlation was also found between plant height and $\mathrm{CO}_{2 \text { int }}$ ( $r=0.438, P=0.002$ ). Within the physiological traits matrix, $P_{n}$ was found to be significantly correlated with $T_{r}(r=0.485, P=0.004)$ and $C_{\text {leaf }}(r=0.559, P=0.001)$, which is similar with a previous study [29]. The $P_{n}$ and $\mathrm{CO}_{\text {2int }}$ were negatively correlated, but not at a significant level in the current study $(r=-0.127, P=0.437)$.

\section{Discussion}

Community assembly in the drawdown area of the TGR

Totally, we identified 190 species, which is comparable to 170 species in a previous study in which the water level raised up to $173 \mathrm{~m}$ in elevation for the first time [13], both of which are lower than that of the pre-dam (377-550) [30, 31]. The results demonstrated that the inundation of the TGR disturb species that cannot tolerate submergence as recently proved by Arias et al. (2018) [23]. When comparing with the UZ (175-180 m) without inundation disturbance, we found that the anti-seasonal WLFs stimulated the plant growth, showing a highest diversity in zone II subjected to moderate inundation of about 90 days. The results are in consistence with those reported by Wittmann et al. (2008) in which tree species richness in the drawdown area ( 45 species/ha) is comparatively higher than that in non-inundated areas (24-36 species/ha) [32]. As mentioned above, inundation period of 90 days is intermediate disturbance in the current study. However, Arias et al. (2013) and Murray-Hudson et al. (2015) both observed plant diversity peaked at the submergence period of 6 months, corresponding to intermediate disturbance [33, 34]. Therefore, IGs vary with regions and time scales, and the diversity patterns are highly corresponding to those species with adaptation to the local hydrology. The lowest species diversities were found at the drawdown zone below $160 \mathrm{~m}$ in elevation (zone IV), indicating that a strong negative effect of inundation has occurred. The long-term submerged area is to some extend similar to perennial flooded area, in which lower diversity exhibit compare to the areas with alternation of wetting and drying [26].

Concerning community structure, both accretion and restriction on plant growth were observed. Community biomass and total coverage were the highest in zone II and lowest in zone IV (Fig. 2b, c). Therefore, there is an underlying direct connection between the anti-seasonal WLFs and the IDH. However, the community height and total coverage were negatively correlated to IGs (Table 1), which is in contradiction with a previous study [35], revealing the shifts in vegetation succession under the anti-seasonal WLFs. Results of GLMs (Table 2) and quadratic analyses (Table 3) both confirmed that IGs were strongly correlated to community structure of biomass, height and coverage. One possible reason is that the WLFs result in a homogenized flooding disturbance within each IG area, which is important for community assembly [36]. The establishment of plant community involves a certain biotic and abiotic factors, plant interand intra-competitions [37]; IGs are found to be important for community structure in the current study. In addition, soil moisture, porosity and nutrient availability, representing the heterogeneity conditions along the 

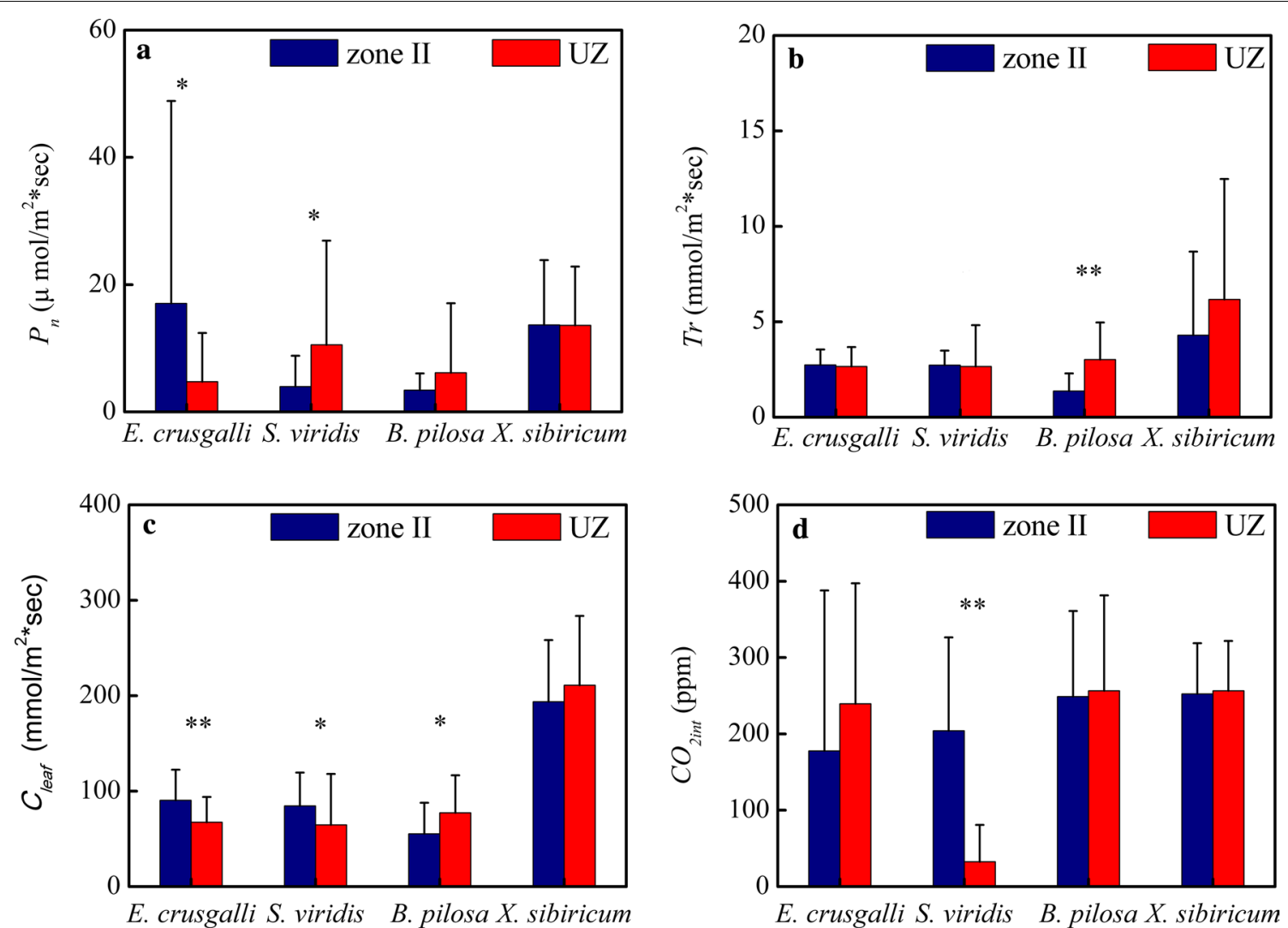

Fig. 4 Physiological traits of the selected dominant plants between zone II and the corresponding upland zone (UZ) of the TGR. * indicates difference of plant trait between zone II and UZ was significant at $P<0.05$; ${ }^{* *}$ indicates difference of plant trait between zone II and UZ was very significant at $P<0.01$

Table 4 The correlations of plant functional traits of the selected species in the TGR region

\begin{tabular}{lllllll}
\hline & $P_{n}$ & $T_{r}$ & $C_{\text {leaf }}$ & CO $_{\text {2int }}$ & Height & Biomass \\
\hline$P_{n}$ & 1 & - & - & - & - & - \\
$T_{r}$ & $0.485^{* *}$ & 1 & - & - & - & - \\
$C_{\text {leaf }}$ & $0.559^{* *}$ & $0.757^{* *}$ & 1 & - & - & - \\
$\mathrm{CO}_{2 \text { int }}$ & -0.127 & 0.261 & 0.308 & 0.253 & $0.438^{*}$ & 1 \\
Height & -0.035 & 0.049 & $0.784^{* *}$ & 0.259 & $0.619^{* *}$ \\
Biomass & $0.349^{*}$ & $0.544^{* *}$ & & 1 \\
\hline
\end{tabular}

$P_{n^{\prime}}$ net photosynthetic rate; $T_{r^{\prime}}$ transpiration rate; $C_{\text {leaf }}$ stomatal conductance and $\mathrm{CO}_{2 \text { int' }}$ intercellular $\mathrm{CO}_{2}$ concentration

${ }^{*} P<0.05,{ }^{* *} P<0.01$

LGs, could be other important variables in explaining the observed diversity, community composition and plant morphological and physiological variables.

\section{Plant's response to the TGR hydrological regime}

The values of morphological traits in zone II were higher than the surrounding uplands (Fig. 3), this may be possibly due to the following reasons: (1) water inundation that may have improved the soil nutrient conditions of the drawdown area, (2) the pattern of the soil seed bank homogenized within each IG area [38, 39], creating a uniform condition for germination and (3) variations in the plant physiological performances. E. crusgalli and $S$. viridis belonging to Gramineae showed similar tendency towards $C_{\text {leaf }}$ and $T_{r}$, while the tendency of Asteraceae plants $B$. pilosa and X. sibiricum was all similar regarding 
$P_{n}, T_{r}, C_{\text {leaf }}$ and $\mathrm{CO}_{2 \text { int }}$. Therefore, plants belonging to the same family or genus show similar feedbacks under the same environmental changes. These were also found in plants of Polygonum (P. cespitosum, P. hydropiper, P. lapathifolium, and P. persicaria) [40]. In the current study, E. crusgalli, S. viridis and B. pilosa are C4 plants [41] which showed significant differences in traits between zone II and UZ, while $X$. sibiricum is a C3 plant and the trait-variations are without significant difference [41, 42]. Generally, C4 plants grow faster and thus higher physiological performances are expected, because individual phenotypic plasticity rather than ecotypic changes leads to the plants adaptation or tolerance to the entire habitat [43]. Plant growth mainly depends on its photosynthetic capacity [44], since $P_{n}$ was positively correlated with $C_{\text {leaf }}$, the increase in $C_{\text {leaf }}$ may facilitate the $P_{n}$ [45]. $T_{r}$ was positively correlated with $C_{\text {leaf }}$ in the current study $(r=0.757$, $P<0.001)$, thus high temperature during summer in the study area may increase both $T_{r}$ and $C_{\text {leaf }}$, and finally promote plant photosynthesis. In addition, positive correlations among $P_{n}, C_{\text {leaf }}$ and plant biomass revealed a relationship between physiological traits and morphological traits. Thereby, plant functional traits are sensitive to flooding disturbance and may illustrate plant's response to the TGR inundation regime. However, questions still exist on how the traits vary along the gradients of inundation and what are the patterns of functional traits among different species. Therefore, in-depth longterm investigations with more species in the drawdown area are suggested. For this purpose, a permanent site has been established in estuary of the Baijia Stream (site 6 in the current study) and the dynamics of vegetation succession were yearly investigated since 2008 [11]; our results are useful for understanding the responses of riparian vegetation to flooding $[11,46,47]$.

\section{Conclusions}

Our results suggest that community assembly in the drawdown area of the TGR is highly correlated with the anti-seasonal WLFs. Shifts in plant diversity and community structure (biomass, height and total coverage) were observed as compared to the UZ (175-180 m). The anti-seasonal WLFs stimulated the plant growth and were found at both community and individual levels. Community biomass, total coverage and diversity are the highest in zone II that was submerged for 90 days, which followed the IDH. GLMs and quadratic analyses showed that IGs were the major factor that led to significant correlation with community structures while the LGs strongly affected diversity patterns. Plant morphological traits showed higher values in the zone II than those in the UZ. Species belonging to the same family showed similar feedbacks on physiological traits. Thus, morphological and physiological traits are sensitive to the flooding, illustrating plant's response to the TGR inundation regime. However, vegetation succession is a time-scale process corresponding to the ecosystem evolution; hence, long-term investigation for studying the vegetation dynamics in response to environmental disturbances such as WLFs is necessary.

\section{Abbreviations \\ TGD: Three Gorges Dam; TGR: Three Gorges Reservoir; IDH: Intermediate Disturbance Hypothesis; WLFs: Water-level fluctuations; UZ: Upland zone; IGs: Inundation gradients; LGs: Longitudinal gradients; SGs: Slope gradients; IEs: Interaction effects; GLMs: Generalized linear models; NAZC: National Agricul- tural Zoning Committee of China; $P_{n}$ : Net photosynthetic rate; $T_{r}$ :Transpiration rate; $C_{\text {leaf }}$ Stomatal conductance; $\mathrm{CO}_{2 \text { int: }}$ Intercellular $\mathrm{CO}_{2}$ concentration.}

\section{Acknowledgements}

We appreciate the contribution for all participants. We thank you Dr. Shangbo Zhou, Dr. Bo Li, Zhiwen Luo, Zongyi He from Chongqing University for helping with field investigation. We appreciate support from the Pengxi River Wetland Research Station and Pengxi River Wetland Natural Reserve Management Bureau.

\section{Authors' contributions}

$Z C$ was responsible for the general design and drafted the manuscript; $X Y$, MRN, $\mathrm{HH}$ and AS contributed to supported the writing of the manuscript. All authors read and approved the final manuscript.

\section{Funding}

This work was funded by the National Natural Science Foundation of China (No. 51809024); the Yangtze project of German Federal Ministry of Education and Research (BMBF) (No. FKZO2WT1141); the China Scholarship Council (CSC) (No. 2011605031) and the Fundamental Research Funds for the Central Universities (No. 2019CDYGYB028).

\section{Availability of data and materials}

The datasets used and/or analyzed during the current study are available from the corresponding author on reasonable request.

Ethics approval and consent to participate Not applicable.

Consent for publication

All authors agreed to publish the paper.

\section{Competing interest}

The authors declare that they have no competing interests.

\section{Author details}

${ }^{1}$ Key Laboratory of the Three Gorges Reservoir Region's Eco-Environment, Ministry of Education, Chongqing University, 400045 Chongqing, People's Republic of China. ${ }^{2}$ Institute for Environmental Research (Biology V), RWTH Aachen University, Worringerweg 1, 52074 Aachen, Germany. ${ }^{3}$ Faculty of Architecture and Urban Planning, Chongqing University, 400044 Chongqing, People's Republic of China. ${ }^{4}$ Department of Evolutionary Ecology and Environmental Toxicology, Goethe University Frankfurt, Max-von-Laue-Str. 13, 60438 Frankfurt am Main, Germany. ${ }^{5}$ School of the Environment, Nanjing University, Xianling Av. 163, 210023 Nanjing, People's Republic of China. ${ }^{6}$ Key Laboratory of Yangtze River Water Environment, Ministry of Education, Tongji University, 200092 Shanghai, People's Republic of China.

Received: 14 February 2020 Accepted: 30 April 2020

Published online: 12 May 2020 


\section{References}

1. Leira M, Cantonati M (2008) Effects of water-level fluctuations on lakes: an annotated bibliography. Hydrobiologia 613:171-184. https://doi. org/10.1007/s10750-008-9465-2

2. Solari L, Van Oorschot M, Belletti B, Hendriks D, Rinaldi M, Vargas-Luna A (2016) Advances on modelling riparian vegetation-hydromorphology interactions. River Res Appl 32:164-178. https://doi.org/10.1002/rra.2910

3. Gurnell A (2014) Plants as river system engineers. Earth Surf Proc Land 39:4-25. https://doi.org/10.1002/esp.3397

4. Brownstein G, Johns C, Fletcher A, Pritchard D, Erskine PD (2015) Ecotones as indicators: boundary properties in wetland-woodland transition zones. Commun Ecol 16:235-243. https://doi.org/10.1556/168.2015.16.2.11

5. Blom CWPM (1999) Adaptations to flooding stress: from plant community to molecule. Plant Biol 1:261-273

6. Nilsson C, Svedmark M (2002) Basic principles and ecological consequences of changing water regimes: riparian plant communities. Environ Manage 30:468-480. https://doi.org/10.1007/s00267-002-2735-2

7. Johansson ME, Nilsson C (2003) Responses of riparian plants to flooding in free-flowing and regulated boreal rivers: an experimental study. J Ecol 39:971-986

8. Jansson R, Zinko U, Merritt DM, Nilsson C (2005) Hydrochory increases riparian plant species richness: a comparison between a free-flowing and a regulated river. J Ecol 93:1094-1103. https://doi.org/10.111 1/j.1365-2745.2005.01057.x

9. Nilsson C, Brown RL, Jansson R, Merritt DM (2010) The role of hydrochory in structuring riparian and wetland vegetation. Biol Rev Camb Philos Soc 85:837-858. https://doi.org/10.1111/j.1469-185X.2010.00129x

10. Merritt DM, Scott ML, LeRoy Poff N, Auble GT, Lytle DA (2010) Theory, methods and tools for determining environmental flows for riparian vegetation: riparian vegetation-flow response guilds. Freshwater Biol 55:206-225. https://doi.org/10.1111/j.1365-2427.2009.02206.x

11. Willison JHM, Li R, Yuan X (2013) Conservation and ecofriendly utilization of wetlands associated with the Three Gorges Reservoir. Environ Sci Pollut Res 20:6907-6916

12. Sun R, Yuan X, Chen Z, Zhang Y, Liu H (2012) Effect of three gorges reservoir (Yangzi River) on the plant species richness in drawdown zone of downstream the tributary river (Pengxi River). Russ J Ecol 43:307-314

13. Wang Q, Yuan XZ, Liu H, Zhang YW, Cheng ZL, Li B (2012) Effect of longterm winter flooding on the vascular flora in the drawdown area of the Three Gorges Reservoir, China. Pol J Ecol 60:95-106

14. Zhang Z, Wan C, Zheng Z, Hu L, Feng K, Chang J, Xie P (2013) Plant community characteristics and their responses to environmental factors in the water level fluctuation zone of the three gorges reservoir in China. Environ Sci Pollut Res 20:7080-7091. https://doi.org/10.1007/s1135 6-013-1702-1

15. Tian Z, Chen W, Zhao C, Chen Y, Zheng B (2007) Plant biodiversity and its conservation strategy in the inundation and resettlement districts of the Yangtze Three Gorges, China. Acta Ecological Sinica 27:3110-3118. https ://doi.org/10.1016/S1872-2032(07)60065-1

16. van der Valk AG (2005) Water-level fluctuations in North American prairie wetlands. Hydrobiologia 539:171-188. https://doi.org/10.1007/s1075 0-004-4866-3

17. Middleton BA, van der Valk AG, Davis CB (2015) Responses to water depth and clipping of twenty-three plant species in an Indian monsoonal wetland. Aquat Bot 126:38-47. https://doi.org/10.1016/j.aquabot.2015.06.004

18. Lite SJ, Bagstad KJ, Stromberg JC (2005) Riparian plant species richness along lateral and longitudinal gradients of water stress and flood disturbance, San Pedro River, Arizona, USA. J Arid Environ 63:785-813. https:// doi.org/10.1016/j.jaridenv.2005.03.026

19. Cronin G Jr, Lewis WM, Schiehser MA (2006) Influence of freshwater macrophytes on the littoral ecosystem structure and function of a young Colorado reservoir. Aquat Bot 85:37-43. https://doi.org/10.1016/j.aquab ot.2006.01.011

20. Crawford RMM (1996) Whole plant adaptations to fluctuating water tables. Folia Geobot Phytotax 31:7-24

21. Moore JE, Franklin SB, Grubaugh JW (2011) Herbaceous plant community responses to fluctuations in hydrology: using Mississippi River islands as models for plant community assembly. J Torrey Bot Soc 138:177-191. https://doi.org/10.3159/torrey-d-11-00011.1

22. Susarla S, Medina VF, McCutcheon SC (2002) Phytoremediation: an ecological solution to organic chemical contamination. Ecol Eng 18:647-658
23. Arias ME, Wittmann F, Parolin P, Murray-Hudson M, Cochrane TA (2018) Interactions between flooding and upland disturbance drives species diversity in large river floodplains. Hydrobiologia 814:5-17. https://doi. org/10.1007/s10750-016-2664-3

24. Violle C, Navas M-L, Vile D, Kazakou E, Fortunel C, Hummel I, Garnier E (2007) Let the concept of trait be functional! Oikos 116:882-892. https:// doi.org/10.1111/j.0030-1299.2007.15559.x

25. Lavorel S, Garnier E (2002) Predicting changes in community composition and ecosystem functioning from plant traits: revisiting the Holy Grail. Func Ecol 16:545-556

26. Wang Q, Yuan X, Willison JHM, Zhang Y, Liu H (2014) Diversity and aboveground biomass patterns of vascular flora induced by flooding in the drawdown area of China's Three Gorges Reservoir. PLoS ONE 9:1-12. https //doi.org/10.1371/journal.pone.0100889

27. NAZC (1984) Technical regulations for land use status survey, committee Naz, eds. Beijing

28. You X, Liu J, Zhang L (2015) Ecological modeling of riparian vegetation under disturbances: a review. Ecol Model 318:293-300. https://doi. org/10.1016/j.ecolmodel.2015.07.002

29. Li M, Yang D, Li W (2007) Leaf gas exchange characteristics and chlorophyll fluorescence of three wetland plants in response to long-term soil flooding. Photosynthetica 45:222-228

30. Wang Y, Li EH, Wu JQ (2002) A preliminary study on the vascular plant flora of the water-level-fluctuation zone in the Three Gorges Reservoir area. J Wuhan Bot Res 20:265-274

31. Tian ZQ, Chen WL, Zhao CM et al (2007) The plant diversity and its conservation in the submersion district and the immigration district of the Three Gorges, China. Acta Ecol Sin 28:3110-3118

32. Wittmann F, Zorzi BT, Tizianel FAT, Urquiza MVS, Faria RR, e Sousa NM, Módena ÉdS, Gamarra RM, Rosa ALM (2008) Tree species composition, structure, and aboveground wood biomass of a riparian forest of the lower miranda river, southern Pantanal, Brazil. Folia Geobotanica 43:397-411. https://doi.org/10.1007/s12224-008-9022-9

33. Arias M, Cochrane T, Norton D, Killeen T, Khon P (2013) The flood pulse as the underlying driver of vegetation in the largest wetland and fishery of the Mekong Basin. Ambio 42:864-876

34. Murray-Hudson M, Wolski P, Cassidy L, Brown M, Thito K, Kashe K, Mosimanyana E (2015) Remote sensing-derived hydroperiod as a predictor of floodplain vegetation composition. Wetl Ecol Manag 23:603-616

35. Chen Z, Yuan X, Liu H, Li B (2012) Effects of water level fluctuation on plant communities in the littoral zone of the Three Gorges Reservoir. Resour Environ Yangtze Basin 21:0672-0677

36. Calcada EA, Lenoir J, Plue J, Broeckx LS, Closset-Kopp D, Hermy M, Decoca $\mathrm{G}$ (2015) Spatial patterns of water-deposited seeds control plant species richness and composition in riparian forest landscapes. Landsc Ecol 30:2133-2146. https://doi.org/10.1007/s10980-015-0236-y

37. Tanentzap A, Lee W, Schulz K (2013) Niches drive peaked and positive relationships between diversity and disturbance in natural ecosystems. Ecosphere 4:133

38. Chen Z, Yuan X, Liu H, Li B, Xu J (2011) Soil seed bank of Xanthum sibircum in newly created wetlands in water-level fluctuation zone of Three Gorges Reservoir. J Southwest China Normal University (Natural Science Edition) 36:0147-0152

39. Chen Z, Liu H, Sun R, Zhang Y, Yuan X (2011) Wetland soil seed bank characters in the littoral zone of Pengxi River of the Three Gorges Reservoir. J Chongqing Normal University (Natural Science) 28:0033-0036

40. Sultan SE, Wilczek AM, Bell DL, Hand G (1998) Physiological response to complex environments in annual Polygonum species of contrasting ecological breadth. Oecologia 115:564-578

41. Carni A, Mucina L (1998) Vegetation of trampled soil dominated by C4 plants in Europe. J Veg Sci 9:45-56

42. Liu MZ, Jiang GM, Li YG, Niu SL, Gao LM, Ding L, Peng Y (2003) Leaf osmotic potentials of 104 plant species in relation to habitats and plant functional types in Hunshandak Sandland, Inner Mongolia, China. Trees 17:554-560. https://doi.org/10.1007/s00468-003-0277-8

43. Sultan SE, Wilczek AM, Hann SD, Brosi BJ (1998) Contrasting ecological breadth of co-occurring annual Polygonum species. J Ecol 86:363-383

44. Ali AA, Xu CG, Rogers A, McDowell NG, Medlyn BE, Fisher RA, Wullschleger SD, Reich PB, Vrugt JA, Bauerle WL, Santiago LS, Wilson CJ (2015) Global-scale environmental control of plant photosynthetic capacity. Ecol Appl 25:2349-2365. https://doi.org/10.1890/14-2111.1.sm 
45. Mielke MS, de Almeida A-AF, Gomes FP, Aguilar MAG, Mangabeira PAO (2003) Leaf gas exchange, chlorophyll fluorescence and growth responses of Genipa americana seedlings to soil flooding. Environ Exp Bot 50:221-231. https://doi.org/10.1016/S0098-8472(03)00036-4

46. Sun R, Yuan X, Ding J (2010) Plant communities in Water-level-fluctuating-zone of Baijia Stream in Three Gorges Reservoir after its initiate impounding to $156 \mathrm{~m}$ height. Wetl Sci 8:1-7

47. Wang Q, Yuan X, Liu H (2014) Influence of the Three Gorges Reservoir on the vegetation of its drawdown area: effects of water submersion and temperature on seed germination of Xanthium sibiricum (Compositae) Pol J Ecol 62:25-36

\section{Publisher's Note}

Springer Nature remains neutral with regard to jurisdictional claims in published maps and institutional affiliations.

\section{Submit your manuscript to a SpringerOpen ${ }^{\circ}$ journal and benefit from:}

- Convenient online submission

- Rigorous peer review

- Open access: articles freely available online

- High visibility within the field

- Retaining the copyright to your article

Submit your next manuscript at $\boldsymbol{\sim}$ springeropen.com 